\title{
Development of Educational Activity of the Social Center in Modern Russia
}

\section{Marina Yakushkina}

\author{
Doctor of Pedagogical Sciences, Head of the Laboratory for the Theory of Formation of Shared Educational Space for \\ CIS countries at St. Petersburg branch of the Federal state budget-funded scientific institution "RAE Institute of \\ Education Management", 2 Chernyakhovskogo Str., 191119, St. Petersburg, vosp_spbgu@mail.ru
}

\begin{abstract}
Marina llakavichus
Candidate of Pedagogical Sciences, Senior Research Scientist of the Laboratory for the Theory of Formation of Shared Educational Space for CIS countries at St. Petersburg branch of the Federal state budget-funded scientific institution "RAE Institute of Education Management", 2 Chernyakhovskogo Str., 191119, St. Petersburg, marinaorlova_99@inbox.ru
\end{abstract}

\section{Doi:10.5901/mjss.2015.v6n6s5p50}

\section{Abstract}

A modern social center provides qualified support for people who have difficulties with full inclusion into social life at various levels. Today, however, change in the activities of social centers is observed due to change in Russia's social and cultural space. The paper examines the problem of change in their traditional activities in relation to the specific character of the institution kind. The paper gives a classification according to the criteria of "organization extent"; "form of ownership"; "functions conditioned by the specific character of the contingent". The paper provides ground for the need of developing cultural and educational orientation of the social centers, creating such institutions as "counseling centers for adults with life problems"; "multi-function centers" where alongside with the traditional programs the educational ones would be implemented. The authors emphasize the growing activity of citizens in educational activities aimed at their self-development. A widely understood result of the mentioned activity direction of social centers is socialization of various age people. It is noted that the inclusion of various centers into the specific territorial cultural and educational space helps disclose their potential in the activity aimed at development of both society and individuals.

Keywords: informal education for adults; social center; adaptation; integration.

\section{Introduction}

In conditions of profound social and economical change in CIS countries, the sphere of social assistance and multifaceted support of life activity of vulnerable groups gains a special significance in society and state care. The need for civil society construction determines the interest for the municipal authorities tier as for the environment of the rise of self-governance. The sphere of cultural and educational activities of social centers at this level is characterized by the pedagogical potential available for formation in representatives of more vulnerable groups of the experience in building relations in various groups and environments, relevant to life in the modern society which keeps changing; for personal development during participation in various forms of interaction in the field of education, leisure, work, various publicspirited social practices. The contradiction between the strategically important objectives set by the country's leaders and difficulties of their implementation has determined the topics range of our study.

Socio-economic situation change in CIS countries, rapidly changing social reality impose high and sometimes conflicting requirements for pedagogics, expand the spheres of its influence, and generate new pedagogical practices.

Orientation to the whole range of intellectual, moral and psychological personality traits is typical for the modern definition and resolution of the problem of education humanitarization and personality development. With regard to this, the formation and development of life position, including finding a public and personal meaning in one's professional and social activities, comes to the foreground.

This situation conditions a particular meaning of interpreting some frequently used previously and today scientific notions explaining a number of pedagogical phenomena. Some of them require more intensive examination, as new life realities bring new interpretations, fill them with a new meaning, allowing for a different consideration of some pedagogical problems that are particularly relevant in contemporary socio-cultural situation. It is to such notions, in our view, that the notion of "pedagogical potential" belongs. 
The notion "pedagogical potential" is rather frequently used in the scientific literature. However, as evidenced by the analysis of the literary sources, various researchers put their own meaning into this term. At the same time, many authors offer notions that are similar to the pedagogical potential, e.g. socio-cultural potential, and even use this term without revealing its contents. Examples of this are works of N.A. Aminov, E.N. Volkova, E.F. Zeer, I.G. Popova, Yu.I. Turchaninova.

Based on the comparative literature analysis we can conclude that the researchers understand pedagogical potential, firstly, as a matter of course, secondly, in a quite ambiguous manner, and thirdly, it is considered in close relation to the activities of the structure the potential of which is explored, e.g. the potential of the supplementary education system, children's holiday camps, various socio-cultural centers, etc. These works contribute to the development of socio-pedagogical potential problem but touch on its separate parts, the problem is not posed as a whole.

The studies described in the literature contribute to the development of pedagogical potential problem, however, they reduce it to the pedagogical abilities, orientation, subjectivity, etc. It is obvious that none of these elements defines in full the notion of "pedagogical potential." Providing mutual influence the elements may produce the compensation phenomenon but the opportunities of compensation vary for various elements. So do the opportunities of development of the elements and the difficulties, associated with development thereof.

In connection to this, we believe the question of the pedagogical potential of social centers to be relevant - one influencing the formation and development of life position of vulnerable segments of population (risk groups), as well as the professional rise of social workers, teachers, etc.

Risk group is a sociological term, a collective definition for members of the population who are the most vulnerable to certain social circumstances or environmental influence. In sociology, the term "risk group" means social groups whose members are vulnerable or may suffer damage from certain medical or social circumstances, as well as the categories of the population which are more prone to criminal or delinquent actions. For instance, the psycho-pedagogical practice considers the notion "children at risk" that traditionally includes children from dysfunctional families, children having delinquent behavior, students having difficulties in education and development, as well as children having chronic illnesses and disabilities. Another example is the psychologists' dealing with the notion "families at risk".

It is suggested to start this study with the analysis of the notion "pedagogical potential" and ones that are close to it: pedagogical potential, educational potential, upbringing potential, social potential, cultural potential, spiritual potential, socio-cultural potential, to identify the conditions for implementation of the pedagogical potential of social centers and the influence of national regional culture on education, socialization of the individual in a social center. Next, we intend to develop theoretical and methodological basis for implementation of pedagogical potential of social centers aimed at resolving the problem of the influence of the pedagogical potential of culture on professional development of social workers, teachers, as well as legal, socio-cultural adaptation of the vulnerable segments of population - people "at risk" (pensioners, single and living alone citizens, children and teenagers "at risk", migrants, people having limited educational needs).

"Modern period of Russia is characterized by abrupt and powerful acceleration of social life. The establishment of various forms of ownership, creation of various political parties and public movements, expanded opportunities to express and defend various view points of view, formation of a democratic, political, ideological, aesthetic and ethic pluralism - all these factors of society transformation and emancipation of an individual make a human be sensible and responsible about his standpoint on much more aspects of life than before" (Shapovalov, 2014). Alongside with the specific historical circumstances of existence, a human life is determined by the existential grounds similar for each and all historical periods. For overcoming various kinds of life crises efficiently, appropriate assistance is essential. This paper discusses the issues of diversity of social centers available in modern Russia and its relevance to socio-cultural problems.

\section{Methodology, Goals and Objectives of the Study}

This study is aimed at developing the theoretical and methodological grounds for implementation of the pedagogical potential of social centers. The need for civil society construction determines the interest for the municipal authorities tier as for the environment of the rise of self-governance. The sphere of cultural and educational activities of social centers at this level is characterized by the pedagogical potential available for formation in representatives of more vulnerable groups of the experience in building relations in various groups and environments, relevant to life in the modern society which keeps changing; for personal development during participation in various forms of interaction in the field of education, leisure, work, various public-spirited social practices. The contradiction between the strategically important objectives set by the country's leaders and difficulties of their implementation has determined the topics range of our study. 
The priority objective of the study is the analysis of educational pedagogical activities of social centers that promote a flexible adaptation of various vulnerable segments of population to the current situation, consideration of the community development dynamics, and prospects for modeling the new educational technologies and opportunities for self-learning and development of adults.

We used the following methodological approaches: system- and activity-based one, axiological one, and andragogical approach. Our methodological principles here are the principle of consistency, principle of complexity of connections and interactions between the elements of the system of pedagogical activity of social centers; the principle of interdependence, complementarity and mutual enrichment of all elements of the system of pedagogical activity of social centers; the principle of unity of the external and internal conditions of pedagogical potential implementation; the principle of diversification; a set of adults education principles; the principle of cultural conformity, conformity to natural laws; the principle of priority of individual rights, the principle of equal rights of ethnic cultures and various religions, reliance on national traditions and taking into account the advanced foreign experience, variability; managing the implementation of the pedagogical potential of social centers as a special way for regulating the relationships between its elements and introducing changes; the principle of objectivity.

To meet the objective set, we expect to use a set of research methods: analysis of home and foreign information sources on the problem under study, modeling, developing, exploring and generalization of the experience of pedagogues and andragogues, sociological surveys, interviews, observation, public expertise method.

\section{Results and Discussion}

When studying the problem of development of pedagogical activities of social centers, it was necessary to define the notion of "social center" more precisely. We treat it as a group subject of the contemporary Russian society for which identification with a social stratum determined on various grounds is unimportant. It can unite people of various ages, lifestyles, material wealth due to its capacity to represent the entire multidimensionality of their interests.

By various kinds of social centers we mean the forms of representation of a specific social institution. Each phenomenon displays its unique shape meditating a range of possible events of cultural and educational field. A social center can provide conditions for sports, recreational and entertainment events. Their focus depends on the intended audience, the existing traditions of leisure activities and it can also set orientation to active types of socio-cultural activities. Providing a place for the activities of various public associations is important today. So what is the difference between the modern social centers and cultural institutions of various levels that are familiar to us from the Soviet period? Their essence is actualization of innovative group and individual forms of work with people of various ages, with the compulsory parameters of democracy, focus on the amateur talent activities and self-governance. The important condition for the successful activity in this case is feasibility and reasoning of activation of developmental potencies of institutions such as family, work teams, educational community, other public structural entities. (Marmor R., Mashaw J., 1988.)

The essence of the definition "social" makes us refer to the community of people which is important for everybody (Barker R., 1982). Understanding the belonging to "those who are not like the others" has become an important humanistic increment of social consciousness. A sick person, an old person, a stranger and a weak person - all of them were rather excluded from relations. Metaphorically, this tradition can be described by the words of Emperor Maximilian's verdict "Deaf means dead". The ancient world in its extreme manifestations (Sparta and Athens) was not strongly concerned about the fate of abnormal people, ones in a severe life situation: in the first case, it was only viable and useful people who had the right to life; in the second case, far not everybody could become citizens having full rights. Unlike the European civilization, the earlier civilizations were more humane. The well-known to all Egyptologists Ebers Papyrus (1550 BC) recorded a kind of training courses for the disabled in the city of Karmaki in those times (A.L. Jastrebitskaya, 1978). The priests taught them music, singing, and massaging - i.e. what was necessary for religious ceremonies. The Evangelic light of charity, mercy and involvement used to soften the hearts of Europeans for more than one century. So early as in the third century A.D., the monastic hospitals and shelters of Byzantium were first mentioned: they served as a refuge for the poor - old, sick, weak people. A rare hagiography makes no mention of such care. The Russian orthodoxy has become familiar with this tradition too. After introduction of Christianity into Russia, the cultivation of Evangelical values towards the world and people had determined the centering of axiosphere of culture. Its citizens got acquainted with the "Christ-like" personality type from the Lives of Saints, first the Byzantine ones, and then from the Russian ones. A surprise at the illogical - in Pagan beliefs - doings of the newly baptized Christians can be described by the words of Saint Pantaleon who had talked to the righteous man he met: "Who are you to live like that? Teach me, I want to live like that too". The numerous versions of Parables about Jesus who appeared in the guise of poor beggars, wanderers and 
the sick men consolidated the need of special attention to these categories by anyone who considered himself to be a Christian. Already in Vladimir Monomakh's "The Sermon", the monarch guides his descendants to good deeds. This knowledge was studied in personal conversations with monks in monasteries, well-doers who struggled at poorhouses by all those who impersonated the Evangelical ideal. The triunity "Monastery-Poorhouse-School" was an institute of beneficence, education and religious upbringing for the popular masses. It can be considered as a prototype of modern social centers. It has a great educational component - just remember the famous monastic libraries. Value relationship with the Orthodox civilization allowed the Russian culture to preserve significant elements of experience in traditions transformed in the process of socio-economic development into regulatory standards. The acquaintance with Western European progressive trends of the Age of Enlightenment has played an important role. The experts point out the three general directions in the development of ideas of social support and education of abnormal people: Christianphilanthropic (objective - social care of people with disabilities; organization form - shelters, poorhouses, almshouses); medical and pedagogical (objective - medical treatment, upbringing and elementary education for children having pronounced developmental disorders, organization form - special departments at hospitals, medical and educational institutions); pedagogical (objective - education of children having hearing, vision troubles, mental disorders, organization form - special classes, special schools and residential care facilities) (N.N. Malofeev, 1996). In Russia as a whole, the movement for inclusion into special social care field of those needing it followed the common European scenario: from activities of individuals (mostly priests, monks and the righteous ones) who were not indifferent to actualization of public initiatives and further on to the public-private partnership in solving the critical social problems. In fact, what we deal with is (self)organization - interchange/combination of two interrelated processes - organization and self-organization.

Traditionally, the idea of helping all kinds of suffering people has been closely connected with the idea of "educating", enlightening them: initially, in accordance with the Christian meaning of this notion - as deification during attainment of Christian truth, as attainment of image, further - as providing the suffering people with knowledge, craft and skills which they will need in the future. Today the education line is traditional for modern social centers: in such a way the concept of lifelong education is implemented (the concept of "Learning to Be", E. Faure). Thus, many practice experts spoke about the need to create multifunction specialized centers that would implement not only the rehabilitation programs (medical and psychological), but also a broadest range of educational programs; the social counseling centers for adults having various life problems are also necessary (A. Dobrynina, 2013.). The programs implemented by the devotees of Pskov socially sheltered workshops in the premises of various kinds of social centers are unfolded within the logic of informal education. What is required is frequently just a coordinating center for monitoring both the demand and volunteer offers, as well as sponsorship opportunities, including ones of the owners of the premises. Experts are discussing the question of creating the personal assistance institution in Russia - a similar to Swedish one yet with the difference that such an assistant can be an individual tutor for self-education, in addition to the functions of helping the client in spheres where the latter has difficulties due to functional disorders.

Development of various types of modern social centers is conditioned by historical change of the recent 30 years. Cultural and educational activities were left without state support so the system carried on in the survival mode. This was especially noticeable in rural areas. Many settlements had no cultural institutions, schools or had only an ungraded elementary school with one teacher. Curtailing the outreach activities enhanced social vulnerability of a large part of the population - first of all children, people having limited educational needs, and retirement age citizens. The pedagogical functions inherent in the system of education were in demand in various social work practices (H. Bahrdt, 2006). All the above has determined, in our opinion, the trend of the social center kinds listed below becoming widespread.

The educational function of a cultural and educational center is implemented in involving the younger generation into the socially significant activities. We can speak about the modern structure of public-private partnership enabling the school to become socially efficient. As common models of cultural and educational centers, such models as "School is a House of culture", "Comprehensive school is a School of Arts", educational and upbringing complex can be named.

The most important directions of work of the above centers are the following:

1. Creating the conditions for pre-school, general education for children and young people, various forms of preprofessional and initial professional training.

2. Studying the conditions of family education, psychological and pedagogical outreach and counseling for parents, attracting public activists to work in hobby groups for children, individual work with families at risk, supporting the institution of family.

3. Organizing public events associated with remarkable events of the village, neighborhood, street, yard, historical dates.

4. Promoting healthy lifestyle by means of developing sports and PE movement of children and adults, equipping the sports and play grounds at places of residence, organizing cultural and recreation rest, maintaining public 
order in micro-society.

5. Attracting children and teenagers to socially useful work: participation in landscaping of surrounding areas, improvement of the settlement and its surroundings, experience of nature protection activities.

6. Volunteering focused on the senior citizens and the disabled, as well as charity events for low-income family children.

7. Lecture-halls, reading conferences, discussion of feature and popular science films and videos.

The work practice of cultural and educational centers in Russia currently identifies the following "soft spots": no social teacher salary in the staff schedule, which at the initial stage of the centers creation increases the load on teachers; non-proven technology of diagnosing the interests and needs of population; underqualified social teachers; incomplete or outdated material and technical base. The inclusion of participants of such centers into implementing the targeted regional programs will allow joining the state initiative with independent social activity of citizens. Such a cooperation of efforts will create an incentive for charity investments into solving the acute social problems. In this context, the objective of creating the supervisory boards at cultural and educational centers is actualized.

In today's Russia, national and regional youth policy programs are created and within them such form as a social and business center gains relevance. Its specific feature is development of youth initiatives and work with various youth segments. In its framework, programs and projects of comprehensive support of the initiatives of each participant concerned are implemented (H. Lampert, 1994).

A modern cultural center implements its activities in integrating the functionally coherent socio-cultural objects and with regard to this uses the favorable conditions for fulfilling the creative leisure potential of its structural units and entities. A powerful result is organization of regional events, socio-cultural programs based on the principle of integration. Such a center is a voluntary association of organizations for culture, sports, public education, information sphere, advertising, service organizations of various forms of ownership having the legal entity status. Full-fledged cultural and educational/cultural and outreach service for people is provided by combining into a single structure of agencies of social institutions such as clubs, library, park zones, museums, educational institutions, and cinemas.

The tradition of organizing social centers (Eng. Social Center, Ital. Centro Sociale, etc.) / communal centers / centers of community (Eng. Community Center) was adopted by Russia as a productive experience of Europe where it is a self-organized communication space basing in a territory specially allocated for it by the local authorities. Today there are various kinds of centers, for example: "creative interest groups", leisure (and care) centers for the senior or children, university community centers, national and cultural, religious centers and many other kinds. When studying such social centers, they have to be separated from state agencies, as well as from the youth countercultural phenomena - "selfgoverned social centers" (Ital. Centro Sociale Autogestito, Eng. Self-managed Social Center).

The modern social centers differ from the traditional Soviet cultural institutions for the large segments of population principally by activity-based emphasizing the group and individual forms of work with various social groups. Without the principle of democracy, promotion and development of processes (self-organization, self-management, etc.), cooperation with institutions of family, labor and academic communities, non-governmental associations brought into life, modern social centers are doomed to failure.

\section{Conclusion}

Modern Russia badly needs organizing cultural and educational activities at social centers that have to be based on the modern pedagogical knowledge of socio-anthropological nature. It is necessary to take a fresh look at the experience of actualization of the social pedagogical potential beyond which no full-fledged personal development or building efficient relationships between social subjects is possible. The pedagogical potential of social centers shall activate the renovation of educational activities for the Russian population regardless of regional identity. The pedagogical potential of social centers is estimated as extremely high in terms of state objective of human resources accumulation.

Today the social centers have to attain the goal of socialization at various levels through their cultural and educational activities. Socialization is meant here not as merely adaptation, but as a process in which an individual's activity converts both the individual's inner world and the wide world of public relations positively. In current conditions, with humanistic paradigm underlying education, social centers can create conditions for coordinating human social and personal development. In connection to this, individualization acts as the principal category that characterizes the pedagogical potential of a social center; it represents a system of tools for continuous support and development of individual talents and life experience.

Today there is social mandate for forming an integral socio-pedagogical infrastructure that is a unified sociocultural organization uniting institutions and services aimed at socio-educational assistance for people of various ages: 
protection of civil rights and liberties, protection of life and health, creation of conditions for a successful career, development of personality and its social adaptation. To achieve such objectives, the socio-pedagogical infrastructure shall be modeled not as a sum of establishments, organizations, etc., but as an environment that develops up to sociocultural features and opportunities of a particular area. The implementation of this concept implies understanding the relevance, importance and comprehensive nature of solution of the set problem by the public and by regional, municipal and federal authorities, as well as understanding the institutional level barriers that hinder cooperation of funds, staff and other social, medical, and pedagogical resources. The cultural and educational, leisure and other centers' solving the problems of involving the population into social transforming activities in the sphere of health, leisure, education, improvement of the environment and public order may be significant for the development of cultural and educational activity.

The potential opportunities of using the results of our research in solving the applied problems are as follows: for legal, socio-cultural, linguistic adaptation of migrants - the use of the entire range of forms and ways of organizing the activity of cultural and educational direction of the RF and other CIS countries municipal social centers; for social support of the retired people - the use of educational, game-based forms of leisure and socially "burning" activity; for developing the programs and agendas of social centers - the use of recommendations, special courses for pedagogical and social workers, special topics for valeology courses (health-saving technologies).

Including all kinds of social centers into an integral cultural and educational space of a certain area actualizes the potential of each institution in solving the tasks of personal and social development.

\section{Acknowledgements}

This publication is supported by RHSF grant No. 15-06-10003.

\section{References}

Malofeev, N.N. Spetsialnoe obrazovanie v Rossii i za rubezhom: $v$ dvuh chastyakh. [Special education in Russia and abroad: in two volumes]. Volume 1 - M.: "Pechatnij Dvor", 1996. - p. 63.

Problemy i perspektivy sotsialno-psihologicheskoi pomoshi detyam i vzroslym s ogranichennymi vozmozhnostyami zdorov'ya i ih sem'yam [Problems and prospects of providing social and psychological assistance to children and adults with disabilities and their families]: a collection of articles on the results of international scientific and practical conference / author A. Dobrynina; Yaroslav-the-Wise Novgorod State University, Veliky Novgorod, 2013. - 88 p.

Shapovalov, V.K. Sotsialnoe obuchenie vzroslykh [Social education of adults]. - M.: "Dashkov and Co", 2014. - p. 11.

Yastrebitskaya, A.L. Zapadnaya Evropa XI - XIII vekov [Western Europe in the XI-XIII centuries]. - M.: Iskusstvo, 1978. - 175 p.

Bahrdt, H.P. Grundformeen sozialer Situationen. Eine kleine Grammatik des Alltagslebens Text. /H.P. Bahrdt München: 2006.

Barker, R. Social Work Dictionary Text. / R. Barker London: 1982.

Lampert, H. Lehrbuch der Socialpolitik. Berlin. Heidelberg. 1994.

Social security: beyond the Rhetoric of Crisis/ Edited by R.T. Marmor. J.L. Mashaw. Princeton: Princeton University Press. 1988.CXV. 167. 